\title{
DA ARTESANIA À APOTEOSE: O TRAJE E A MOVIMENTAÇÃO DAS COMPONENTES DA ALA DAS BAIANAS DE CARNAVAL
}

FROM HANDMADE TO APOTHEOSIS: THE COSTUME AND MOVEMENT OF THE COMPONENTS OF THE BAIANAS WING OF CARNIVAL

\section{DE LA ARTESANÍA A LA APOTEOSIS: EL VESTUARIO Y EL MOVIMIENTO DE LAS COMPONENTES DEL ALA DE BAIANAS DEL CARNAVAL}

\section{Maria Eduarda Andreazzi Borges}

Maria Eduarda Andreazzi Borges

Especialista em Moda \& Criação pela Faculdade Santa Marcelina e Graduada em Comunicação Social - Habilitação em Rádio e TV pela Universidade Metodista de Piracicaba. Atualmente é mestranda em Artes Cênicas pela Escola de Comunicações e Artes da Universidade de São Paulo - ECA USP, sob orientação do Prof. Dr. Fausto Roberto Poço Viana, pesquisando o traje da baiana de Carnaval. Atua como foliã-pesquisadora e componente ativa da ala das baianas da escola de samba Sociedade Rosas de Ouro da cidade de São Paulo, desde 2010. É também integrante dos grupos de pesquisa Fayola Odara e Núcleo de Pesquisas Traje de Cena, Indumentária e Tecnologia. Bolsista CAPES. E-mail: mariaeduardapesquisa@gmail.com. 


\section{Resumo}

O artigo apresenta a trajetória do traje usado pelas componentes da ala das baianas nos desfiles oficiais das escolas de samba, relacionando a sua grande expansão - em termos de maior ornamentação vertical, dimensional e direcional - ao espaço físico onde se desenrola a performance das escolas de samba desde a criação do campeonato em 1932. As principais referências teóricas são CABRAL (2011); FERREIRA (1999 e 2010); CAVALCANTI (2011).

Palavras-chaves: baiana de Carnaval, Carnaval, fantasia, traje de baiana, traje de folguedo

\section{Abstract}

The article presents the trajectory of the costume used by the participants of the baianas wing in the official parades of the samba schools, relating its great expansion - in terms of greater vertical, dimensional and directional ornamentation - to the physical space where the performance of the schools of the samba takes place since the creation of the championship in 1932. The main theoretical references are CABRAL (2011); FERREIRA (1999 and 2010); CAVALCANTI (2011).

Keywords: baiana costume, carnival costume, carnival, folk costume, fancy dress

\section{Resumen}

El artículo presenta la trayectoria del traje que lucieron los integrantes del ala baianas en los desfiles oficiales de las escuelas de samba, relacionando su gran expansión - en términos de mayor ornamentación vertical, dimensional y direcional - con el espacio físico donde se desarrolla la actuación de las escuelas de samba desde la creación del campeonato en 1932. Los principales referentes teóricos son CABRAL (2011); FERREIRA (1999 y 2010); CAVALCANTI (2011).

Palabras clave: baiana de Carnaval, Carnaval, fantasia, traje de fiesta, vestuario de baiana 


\title{
Introdução
}

\begin{abstract}
Muitas senhoras realizaram o desejo do ano inteiro; vestir a bela fantasia de Baiana. Mesmo que o pano da costa seja de Chitão. Um pouco de brilho e tudo vira festa. O que tem mais valia é a alegria de dançar e cantar mostrando a energia que o tempo acumulou. Sejam benditas, para sempre, queridas BAIANAS. (Joãosinho Trinta)
\end{abstract}

Quando falamos de desfiles de Carnaval, logo vem à lembrança figuras icônicas como mestre-sala e porta-bandeira, passistas, bateria e principalmente $-\mathrm{a}$ ala das baianas com seus trajes suntuosos.

Para os pesquisadores Maria Apparecida Urbano e Felipe Ferreira, as baianas compõe "a ala mais esperada" (URBANO, 2012, p. 54) e determinam que "uma escola de samba sem ala das baianas não é uma escola de samba" (FERREIRA, 2010, p. 38). Tal observação não é feita considerando apenas os regulamentos dos desfiles oficiais, que tornam sua presença obrigatória e com número mínimo de componentes, mas sim pelo simbolismo que elas carregam consigo.

As alas de baianas das escolas de samba são uma homenagem às tias baianas, mulheres negras, recém libertas, que viveram na cidade do Rio de Janeiro e no final do século XIX e início do século XX foram as grandes matriarcas do samba. Muitas delas eram adeptas de religiões afro-brasileiras e por este motivo seus trajes, desde os primórdios dos desfiles de escolas de samba, remetem às vestimentas usadas até hoje nos terreiros de Umbanda e Candomblé.

Atualmente, as componentes são mulheres ${ }^{1}$ que atuam nas mais diversas profissões e têm crenças religiosas diversas. Dentro de suas escolas, elas carregam o significado da manutenção da cultura viva do samba,

\footnotetext{
${ }^{1}$ Há também registros de homens vestidos de baiana, principalmente nos primórdios dos desfiles carnavalescos, porém com o passar dos anos a ala foi sendo formada quase que exclusivamente por mulheres, principalmente nos desfiles das escolas de samba do Grupo Especial da LIESA (Rio de Janeiro) onde pelo regulamento, as escolas devem "impedir a presença de pessoas do sexo masculino na Ala de Baianas, exceto Diretores, desde que estes não estejam com a mesma fantasia da Ala em questão" (LIESA, 2020, p. 9).
} 
"representam o elo com o sagrado, visto que são elas que cuidam de todo o 'axé' de uma escola de samba” (ALMEIDA e ROCHA, 2020, p. 73) e ainda, "ajudam a cuidar da roda, da quadra, da escola. Organizam a limpeza, fazem as comidas e preparam as celebrações... São mães e avós dos sambistas, portanto, personagens fundamentais na transmissão do saber do samba, de geração para geração". (IPHAN, 2014, p. 112)

\section{Da artesania}

Criadas por populares, afrodescendentes, moradores de morros e marginalizados pela sociedade da época, as escolas de samba surgiram no final da década de 1920, trazendo para as comemorações carnavalescas um novo modo de celebração do folguedo.

O primeiro campeonato de sambas aconteceu em 1932, na Praça Onze, no Rio de Janeiro, e contou com a presença de dezenove agremiações, sendo que quem se sagrou campeã foi a Grêmio Recreativo Escola de Samba Estação Primeira de Mangueira. O concurso foi promovido pelo Jornal Mundo Sportivo, de propriedade do jornalista Mário Filho (1908-1966), sendo a semente para o que conhecemos hoje como os desfiles oficiais das escolas de samba.

Durante anos, os trajes das baianas de Carnaval foram muito semelhantes ao traje social das tias baianas: com a inserção de enredo, elas foram se tornando personagens, porém ainda mantinham a forma e volume do traje social.

Feitos artesanalmente pelos moradores da comunidade e em sua maioria com recursos próprios, não havia a uniformidade (figura 1) que hoje é exigida pelo regulamento. A manufatura do traje é citada pelo sambista Amauri Raposo no documentário Memória em Verde e Rosa, que informa:

no tempo da minha mãe, a ala das baianas era cada uma fazia tua baiana! Não era... era uma ala de baiana dentro da escola, mas não era aquele padrão de baiana - entendeu? - tudo igual. A mãe do Tantinho fazia uma; a minha mãe fazia outra; minha tia fazia outra e ninguém sabia. Nego só ia saber, só ia ver as baianas no dia (MEMÓRIA, 2017). 
Tia Suluca (1927-) $)^{2}$, conta que os trajes eram simples e que:

\begin{abstract}
a Neuma ${ }^{3}$ - era ela que vestia a gente, dava pano pra gente sair na Mangueira. O pano era tão, tão vagabundo que a gente botava ( $\mathrm{sic}$ ) o luzinha ${ }^{4}$ por cima e botava um forro por baixo. Ali a pessoa botava uma goma no fogo pra cozinhar. Quando a goma tava (sic) meia fria a gente fazia assim para sair aquela goma e pendurava na corda. Ali só ia secando, aí ficava...Ficava aquela roda bonita, justamente onde botava a outra roupa por cima (MEMÓRIA, 2017).
\end{abstract}

Figura 1 - Trajes diferentes na mesma ala. Desfile da G.R.E.S. Estação Primeira de Mangueira (RJ) no Carnaval 1960.

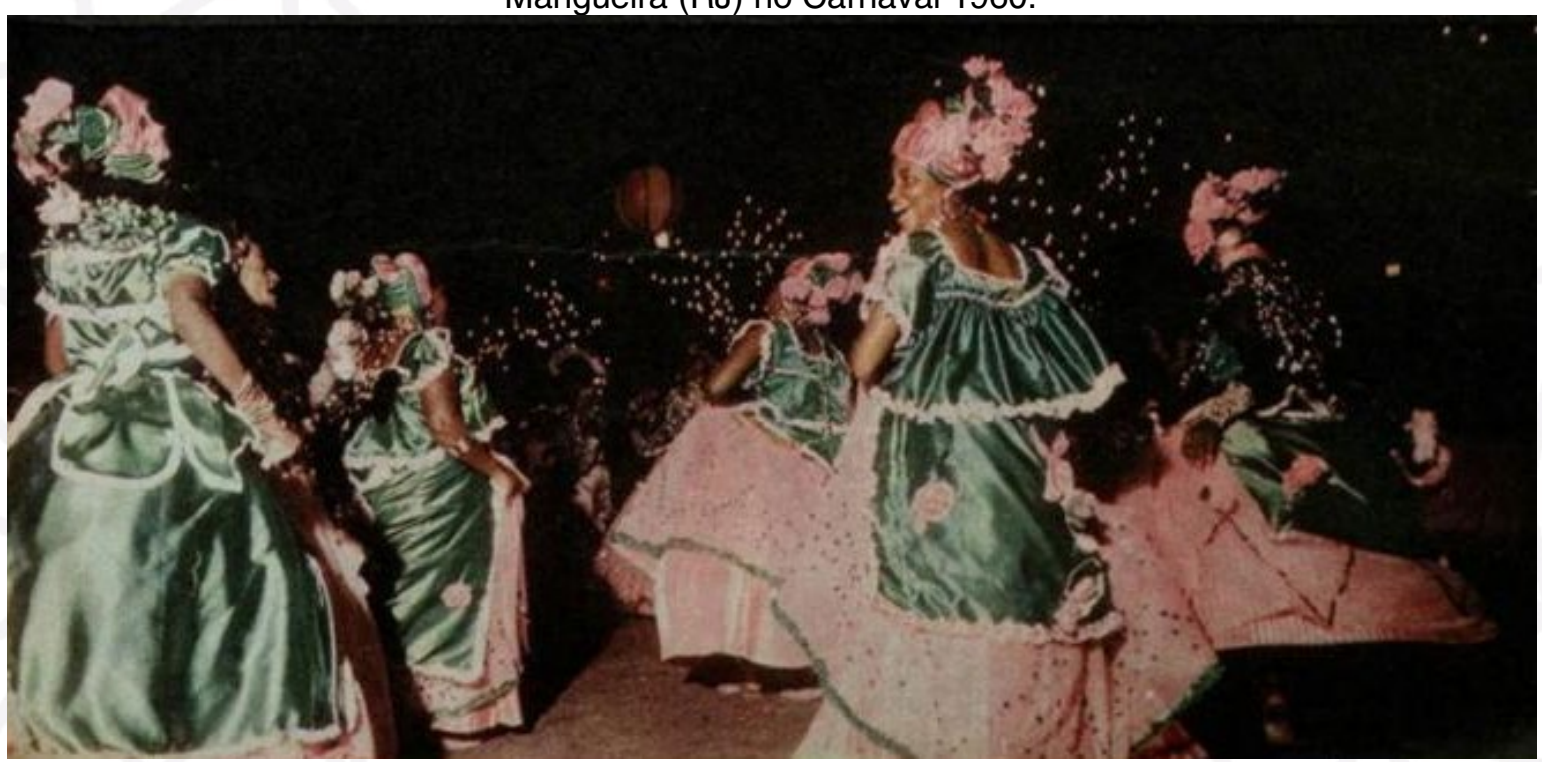

Foto: Revista O Cruzeiro Ano 1960lEdição 0021 (Disponível em:

http://memoria.bn.br/DocReader/DocReader.aspx?bib=003581\&pagfis=1296996 Acesso em 28 mar. 2021).

Estes trajes, são considerados mais simples em relação aos atuais, possibilitavam a liberdade de movimento para as baianas, que poderiam executar sem muito esforço seu bailado e giros, no momento em que o corpo estava motivado a dançar.

Outra questão sobre a formação é que nos primórdios dos desfiles, as alas não eram apresentadas em blocos. Muitas vezes se misturavam uns aos outros. No caso das baianas, muitas vezes as componentes vinham nas laterais do desfile (observar posição das baianas nas figuras 2 e 3).

\footnotetext{
${ }^{2}$ Arlette da Silva Fialho é baluarte e presidente de honra da Ala das Baianas da G.R.E.S. Estação Primeira de Mangueira.

${ }^{3}$ Neuma Gonçalves da Silva (1922-2000) foi uma sambista na cidade do Rio de Janeiro.

${ }^{4}$ Segundo von Simson "Iuzinha" eram "geralmente cetim e o lamê" (VON SIMSON, 2007, p.167) que recebiam esse nome por causa do seu brilho.
} 
Figura 2 - Ala das Baianas da G.R.E.S. Império Serrano (RJ) no desfile de Carnaval de 1956.

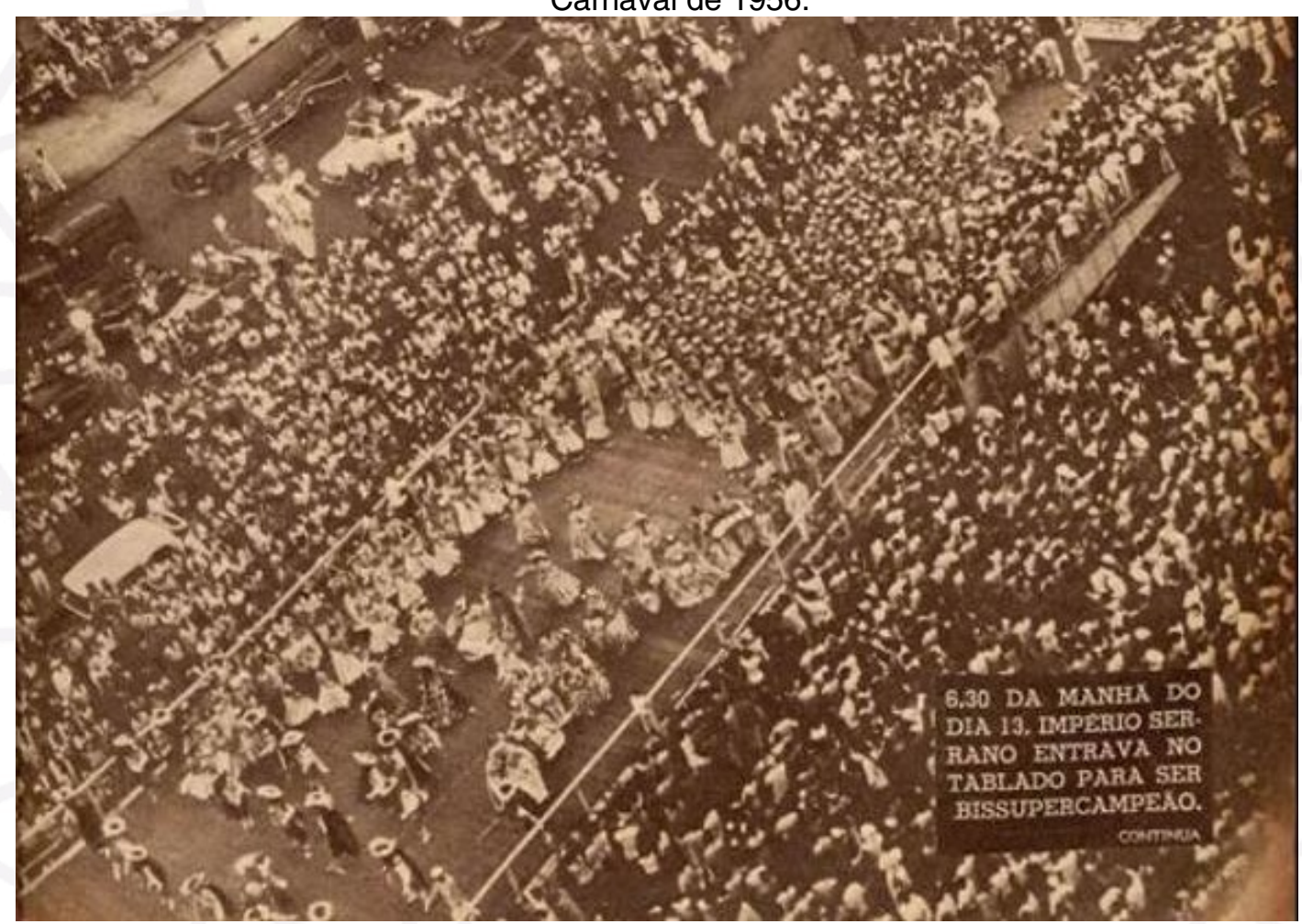

Foto: Revista O Cruzeiro Ano 1956|Edição 0020 (Disponível em:

http://memoria.bn.br/DocReader/DocReader.aspx?bib=003581\&pagfis=103563. Acesso em 22 mar. 2021).

Figura 3 - Na parte esquerda e superior da foto é possível identificarmos algumas componentes da ala das baianas na lateral do desfile da G.R.E.S. Império Serrano (RJ) no desfile de Carnaval de 1956.



Foto: Revista Manchete Ano 1956ไEdição 0200 (Disponível em:http://memoria.bn.br/DocReader/docreader.aspx?bib=004120\&pasta=ano\%20195\&pesq $=$ \&pagfis=13371. Acesso em 22 mar. 2021). 
Em meados da década de 1950 começam mudanças muito significativas, tanto na organização das escolas de samba, onde o samba começa a ser apreciado pela classe média brasileira e por personalidades internacionais, inclusive autoridades, que começam a frequentar os ensaios das escolas, em território antes restrito às pessoas da comunidade, do morro, quanto nos concursos com mudanças nos locais do desfile em que o espaço foi ampliando e começaram a ser montadas estruturas de arquibancadas para os espectadores com os ingressos cada vez mais disputados para assistir ao desfile. Tais modificações então começarão a refletir diretamente na movimentação dos componentes e também em seus trajes.

A G.R.E.S. Acadêmicos do Salgueiro é considerada a grande percursora da mudança nos desfiles. No Carnaval de 1959, o presidente Nélson de Andrade, querendo sobressair em relação às outras escolas, convidou o casal Dirceu Nery ${ }^{5}$ (1919 -1967) e Marie Louise Nery ${ }^{6}$ (1924-2020) para serem os responsáveis pela concepção e criação do enredo "Viagem Pitoresca e Histórica ao Brasil"7. Era a abertura para a entrada de pessoas ligadas às artes e acadêmicos nas escolas de samba. Até então, quem realizava a parte visual dos desfiles eram artesãos das próprias comunidades.

O pesquisador e jornalista Sérgio Cabral relata que Marie Louise ficou responsável pelas fantasias "respeitando fielmente os figurinos da época [1816], mudando apenas as cores originais, pois, em 1959, nenhuma escola de samba desfilava com fantasias que não ostentassem as suas cores", enquanto Dirceu "cuidou das alegorias e dos adereços, abandonando os grandes carros e criando adereços que os componentes trariam nas mãos" (CABRAL, 2011, p.197).

A escola terminou na segunda posição. Ainda não querendo ser "nem melhor nem pior. Apenas uma escola diferente.", o presidente convida o

\footnotetext{
${ }^{5}$ Cenógrafo e aderecista brasileiro.

${ }^{6}$ Cenógrafa, aderecista, figurinista e professora universitária. É considerada a primeira mulher como carnavalesca de uma escola de samba.

${ }^{7} \mathrm{O}$ enredo é homônimo à obra do francês Jean-Baptiste Debret na qual ele relata por meio de texto e gravuras a sua experiência no Brasil, durante a missão francesa trazida por Dom João VI em 1816.

${ }^{8}$ Ainda hoje é o lema da escola.
} 
cenógrafo Fernando Pamplona (1926-2013) ${ }^{9}$ para fazer o Carnaval de 1960.

Este aceitou o convite, exigindo que o casal Dirceu e Marie Louise continuasse na escola. Agregou na equipe Arlindo Rodrigues (1931-1987) ${ }^{10}$ e Nilton Sá ${ }^{11}$.

Feito o acordo, o enredo proposto foi "Quilombo dos Palmares", contando a história de Zumbi dos Palmares, figura que até então era pouco conhecida na história do Brasil, exaltando a luta negra. Nesse ano, a escola apresentou duas alas de baiana: a primeira no quadro da formação do Quilombo e "carregavam bandeiras vermelhas simbolizando a revolução"; a segunda no quadro da Nação Livre "dessa vez trazendo consigo bandeiras brancas, simbolizando a paz" (figura 4) (SALGUEIRO, 2021).

Figura 4 - Ala das baianas do G.R.E.S. Acadêmicos do Salgueiro (RJ) no Carnaval de 1960.

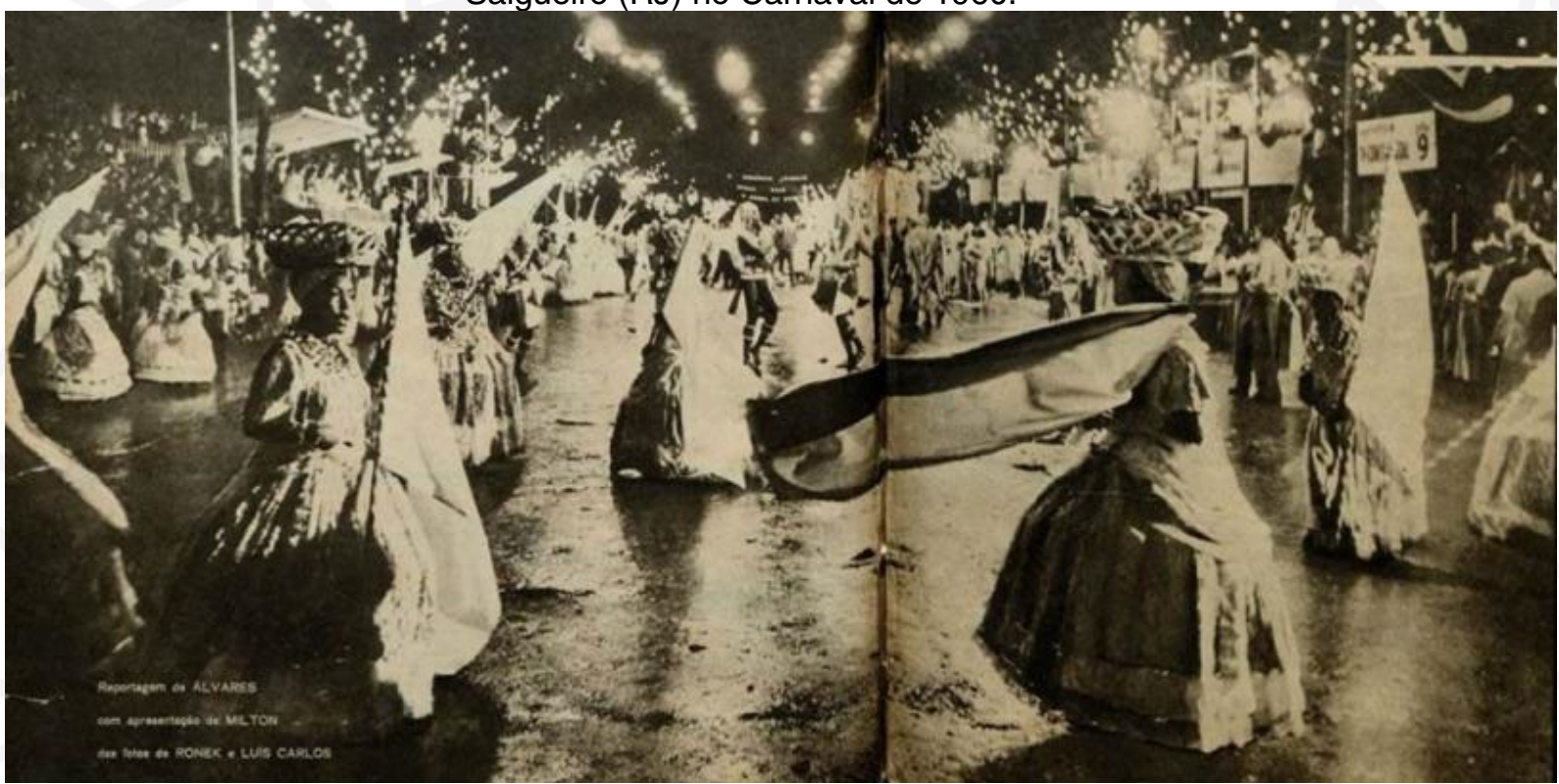

Foto: Revista O Cruzeiro Ano 1960lEdição 0023 (Disponível em:

http://memoria.bn.br/DocReader/DocReader.aspx?bib=003581\&pagfis=129880. Acesso em: 22 mar. 2021).

A década de 1960, será então considerada a com a maior expansão dos desfiles das escolas de samba no Carnaval principalmente no que se

\footnotetext{
${ }^{9}$ No Carnaval de 1959 foi jurado nos quesitos escultura e riqueza, sendo o único a atribuir uma nota maior do que da Portela que foi a grande campeã. Trabalhava no setor de cenografia do Teatro Municipal do Rio de Janeiro e já havia vencido diversos concursos de decoração de bailes carnavalescos do Teatro e também em disputas pela decoração da cidade nos dias de Carnaval. ${ }^{10}$ Cenógrafo e figurinista do Teatro Municipal do Rio de Janeiro. Atualmente é considerado um dos maiores carnavalescos da história do Brasil.

${ }^{11}$ Desenhista e aderecista.
} 
refere a crescimento "em importância e tamanho e tornando-se principal expressão do carnaval brasileiro" (FERREIRA, 2010. p.39), pois, para além da absorção de profissionais das visualidades, nas escolas de samba, acontecessem as primeiras transmissões televisivas dos desfiles ${ }^{12}$ e a com contagem de tempo para a passagem das escolas, inclusive com punição para quem não o cumprisse. Já na cidade de São Paulo, houve a oficialização dos concursos de desfiles de escolas de samba, em 1968.

As mudanças continuam e os participantes, que eram apenas celebrantes de uma festa popular, serão cada vez mais inseridos como personagens do enredo de um grande espetáculo.

\section{A apoteose}

"A gente tira a força não sabe de onde (...). Eu sei que o negócio é bom para caramba. Não quero largar disso não!". Wania Calado, Baiana do Salgueiro. (CAVALCANTI, 2011, p. 4)

Com a expansão e transformação de festa popular em verdadeiro espetáculo audiovisual, rendendo lucros, houve a necessidade da construção de um local específico para seu acontecimento. Entre as décadas de 1980 e 1990, foram construídos os sambódromos nas cidades do Rio de Janeiro ${ }^{13} \mathrm{e}$ de São Paulo ${ }^{14}$, ambos projetados pelo arquiteto Oscar Niemeyer.

Após o aumento na altura das arquibancadas e a profissionalização das transmissões televisivas, os trajes tiveram que ter uma mudança significativa em relação à ornamentação tanto vertical (aumentando a altura), dimensional (aumento aparente no tamanho do corpo) e direcional (para realçar os movimentos do corpo com detalhes soltos) (FERREIRA, 1999, p. 105), para que assim pudessem ter maior visibilidade

Atualmente o traje de folguedo da ala das baianas é basicamente composto por: saiote de estrutura ou saia já estruturada; saia adereçada e

\footnotetext{
${ }^{12}$ Apenas com flashes dos desfiles cariocas.

${ }^{13}$ Inaugurado em 1984, hoje a pista de desfiles tem 700 metros de extensão e 13 metros de largura.

${ }^{14}$ Inaugurada a primeira parte em 1991, hoje a pista de desfiles tem 530 metros de extensão por 14 metros de largura.
} 
podendo haver também sobressaia; blusa; costeiro e chapéu ${ }^{15}$, sendo pensados pelo carnavalesco - ou também por uma equipe, se houver.

Depois de concebidos e desenhados, faz-se uma peça piloto para as aprovações e acertos necessários. Na sequência começa a reprodução pelos ateliês das escolas.

No desfile, o traje da baiana, traje de folguedo, deve vestir a ala por completo e de forma uniforme ${ }^{16}$. Caso haja mais de um tipo de traje, deverá ser indicado no Livro Abre-Alas ou na Pasta dos Jurados ${ }^{17}$. Podem ser chamados de fantasias do enredo, pois assim como as outras alas, as componentes da ala das baianas serão personagens do enredo, que é "a criação e a apresentação artística de um tema ou conceito" (LIESA, 2020, p. 46). Para o julgamento no quesito fantasia há três pontos de avaliação técnicas: uniformidade, acabamento e realização.

Desse modo, por representar um personagem do enredo, os trajes foram modificando suas formas e volumes (figuras 5 e 6$)^{18}$ e também perdendo, em alguns carnavais ${ }^{19}$, partes mais características do seu traje, como o pano da costa, que usualmente é substituído pelo costeiro e gravata; tecidos de renda por tecidos com brilho; o uso do turbante por chapéus adereçados; e a extinção do uso de colares e pulseiras pessoais.

\footnotetext{
${ }^{15}$ Para mais informações: BORGES, Maria Eduarda Andreazzi. Baú de reminiscências: alguns trajes das componentes da ala das baianas de Carnaval In: Dos bastidores eu vejo o mundo: cenografia, figurino, maquiagem e mais: vol. IV. 1a. ed. São Paulo: ECA USP, 2020, p. 169-193. Disponível em: http://www.livrosabertos.sibi.usp.br/portaldelivrosUSP/catalog/book/541. Acesso em: 22 mar. 2021.

${ }^{16}$ Diferentemente do que acontecia quando os trajes eram confeccionados individualmente por cada uma das componentes.

${ }^{17}$ Documentos que devem ser entregues pelas escolas de samba contendo informações e imagens do desfile. No Rio de Janeiro ele é chamado de Livro Abre-Alas e em São Paulo de Pasta dos Jurados.

${ }^{18}$ As silhuetas foram analisadas a partir de um panorama geral, mas é importante destacar que estamos tratando de um evento que é um organismo vivo na sociedade, em que vai se adequando conforme as criações propostas pelos carnavalescos e também as tradições de cada agremiação que têm o desejo de se consagrarem campeãs, mas principalmente pela personagem que a ala das baianas representará.

${ }^{19}$ Quando a personagem representada por elas não remete à figura tradicional de baiana.
} 
Figura 5 - Silhuetas do traje da ala das baianas no século XX.

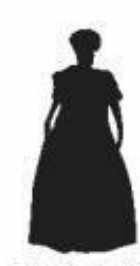

Década de 1930

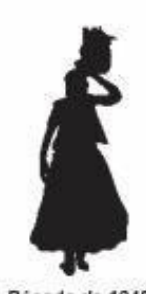

Década de 1940

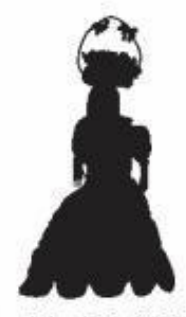

Década de 1950

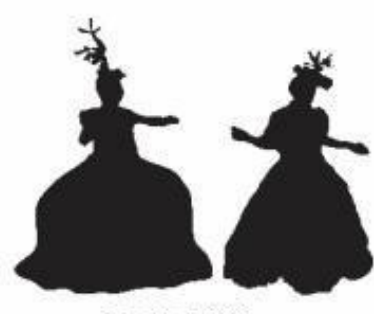

Década de 1960

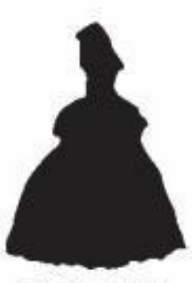

Década de 1970

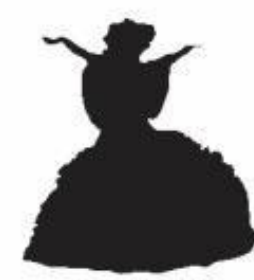

Década de 1980

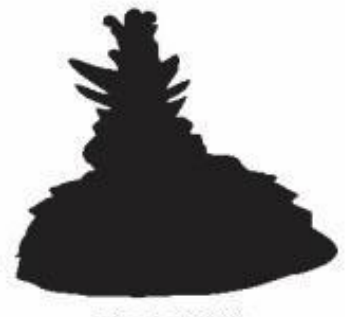

Década de 1990

Desenhos: Maria Eduarda Andreazzi Borges.

Figura 6 - Silhuetas do traje da ala das baianas no século XXI.

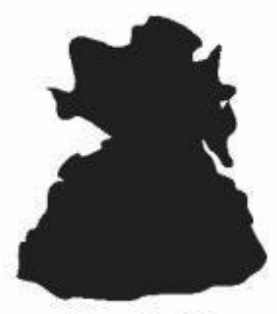

Década de 2000

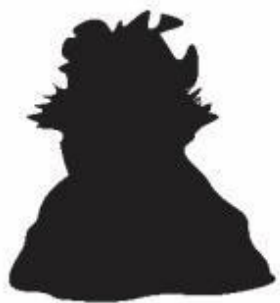

Década de 2010

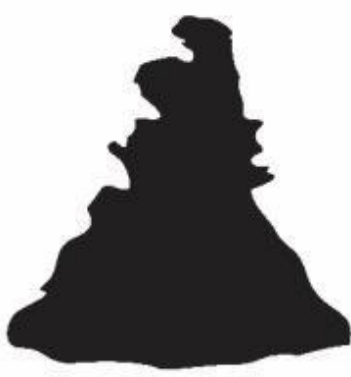

Década de 2020

Desenhos: Maria Eduarda Andreazzi Borges.

Porém com todas as modificações dos últimos anos, os trajes foram, em sua maioria, limitando muito os movimentos das componentes, pois ganharam dimensões enormes e muito peso. Hoje eles chegam a ter a roda da saia em média de 5 a 7 metros e pesando 20 a 25 quilos, dificultando a performance das componentes mais velhas durante a passagem pelas passarelas do samba.

A dança das baianas era anteriormente mais espontânea: seus corpos giravam quando elas queriam, os braços se movimentavam ao som da emoção do samba. Hoje, com a normatização das alas onde pelos critérios de avaliação de harmonia e evolução a ala das baianas devem se apresentar em um bloco conciso sem "buracos" e com o alinhamento de fila e coluna o mais reto que for possível e também a restrição dos movimentos pelo traje, o 
bailado é basicamente coreografado, principalmente nos giros que acontecem nos refrões.

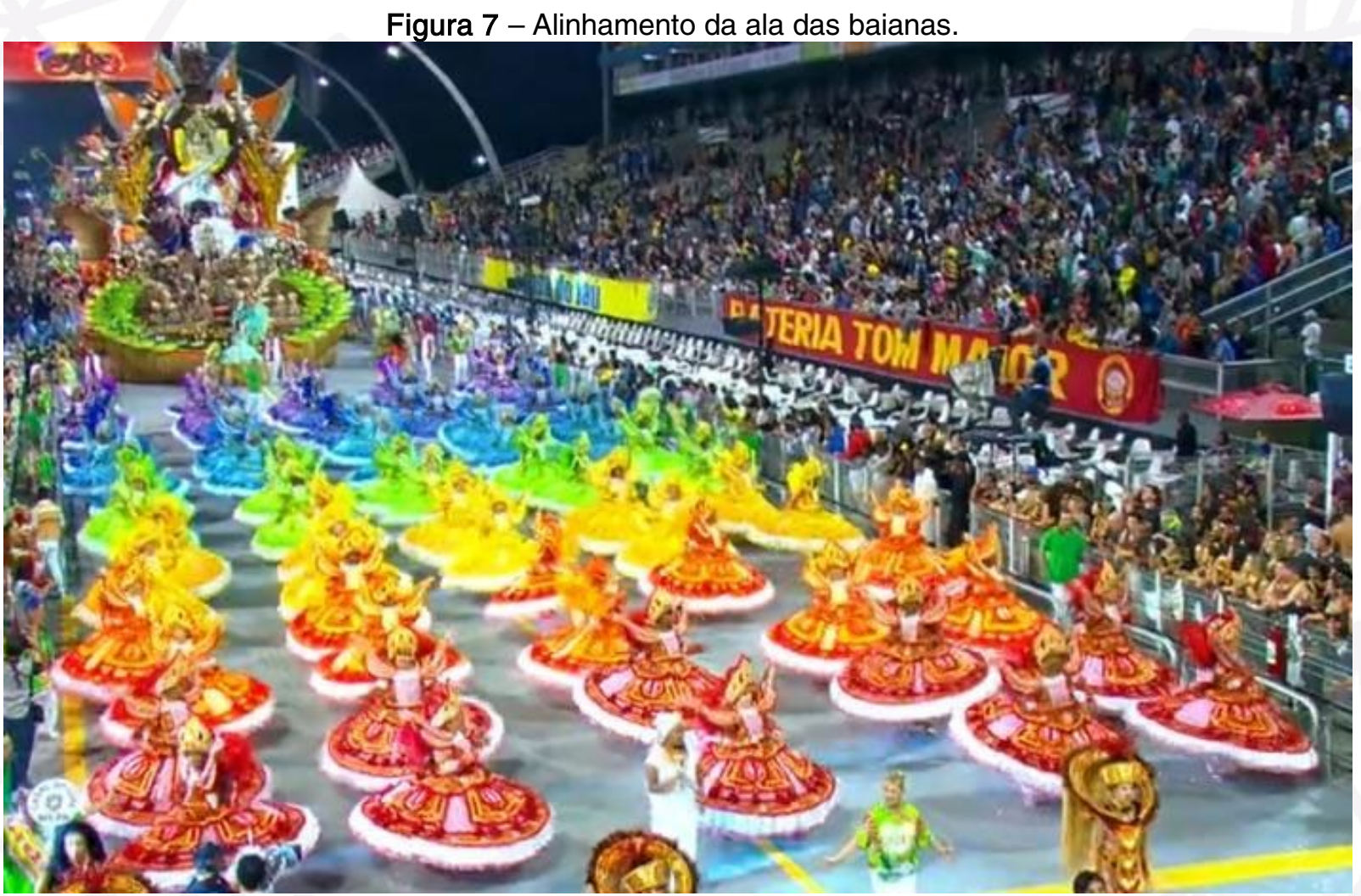

Foto: Print do desfile (Disponível em: https://globoplay.globo.com/v/7386552/programa/. Acesso em: 22 mar. 2021).

O movimento de giro das baianas não é apenas um elemento coreográfico, mas sim traz todo o significado de sua existência, pois,

\begin{abstract}
com o giro de seu corpo, a Baiana é a imagem encarnada da tradição e aciona todo um universo de valores associado ao feminino e aos avós. É pródiga e acolhedora, "dá força" para os jovens que a prestigiam, goza de autoridade ímpar. Toda escola "ouve muito" suas baianas, e a autoridade a elas atribuída e a deferência (CAVALCANTI, 2011, p. 24).
\end{abstract}

Visualmente eles aparentam ter muita velocidade, principalmente pelo movimento que os trajes podem executar, mas não é assim que acontece. A movimentação deve ser realizada calmamente, para que não haja risco de queda. Se o giro for feito com muita velocidade e força, ao parar, a parte da saia que é estruturada tenderá a continuar em movimento, fazendo com que a parte de baixo do traje tire o corpo do eixo de equilíbrio. 
Da artesania à apoteose: o traje e a movimentação das componentes da ala das baianas de Carnaval

Caso a saia seja feita com tecido e forro leve, o que acontece com mais frequências nas escolas dos grupos inferiores de acesso, o giro deverá ser ainda mais lento, pois ela ganhará ainda mais velocidade na movimentação.

Assim, são os movimentos do corpo como um todo que fazem com que o traje tenha essa aparência de movimento intenso.



Foto: Site Portela Web (Disponível em: https://www.portelaweb.org/segmentos/baianas. Acesso em 28 mar. 2021).

Para além dos giros, na performance das baianas durante o desfile na avenida, também há o gingado da saia. Tal movimento é conseguido com uma pequena movimentação do corpo em forma de pêndulo, indo da direita para a esquerda consecutivamente, enquanto a baiana caminha. 
Figura 9 - Movimentação da saia no bailado.

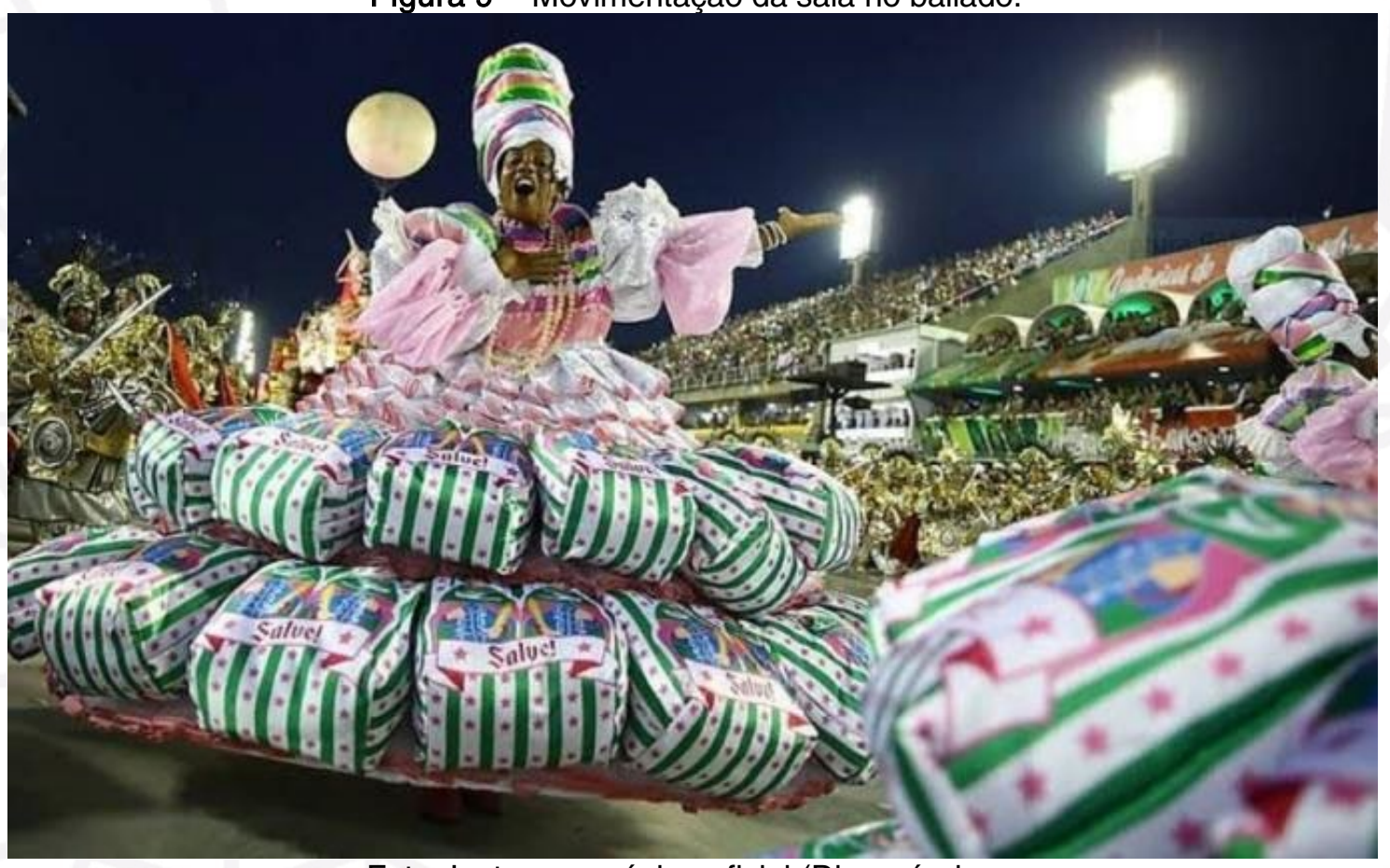

Foto: Instagram página oficial (Disponível em:

https://www.instagram.com/p/CB8LLhXBKem/?igshid=11nw9yryqc5e1. Acesso em: 22 fev. 2021).

Outros movimentos também poderão ser limitados pelo traje, como os movimentos dos braços, no caso de o costeiro ser muito grande e adereçado: só será possível movimentar a parte inferior dos braços e as mãos. A movimentação de pescoço e cabeça, caso o chapéu, ou adereço de cabeça, não seja desenvolvido corretamente observando a questão de eixo de peso e principalmente a curvatura que se adequa à cabeça da componente, ficará pendendo para os lados e pode cair no movimento.

\section{Considerações finais}

Atualmente, há algumas razões para o êxodo das componentes da ala das baianas. Um deles é que com o avançar da idade, a baiana não aguenta mais o peso dos trajes, não permitindo sua movimentação (já restrita pela idade) com desenvoltura. Na maioria das vezes elas são encaminhadas para a Velha Guarda da escola. Mesmo assim, hoje há baianas que desfilam por mais de uma escola no mesmo campeonato carnavalesco. 
Figura 10 - Ala das baianas da G.R.E.S. São Clemente (RJ) no Carnaval 2019. Crítica pela falta de componentes nas escolas.

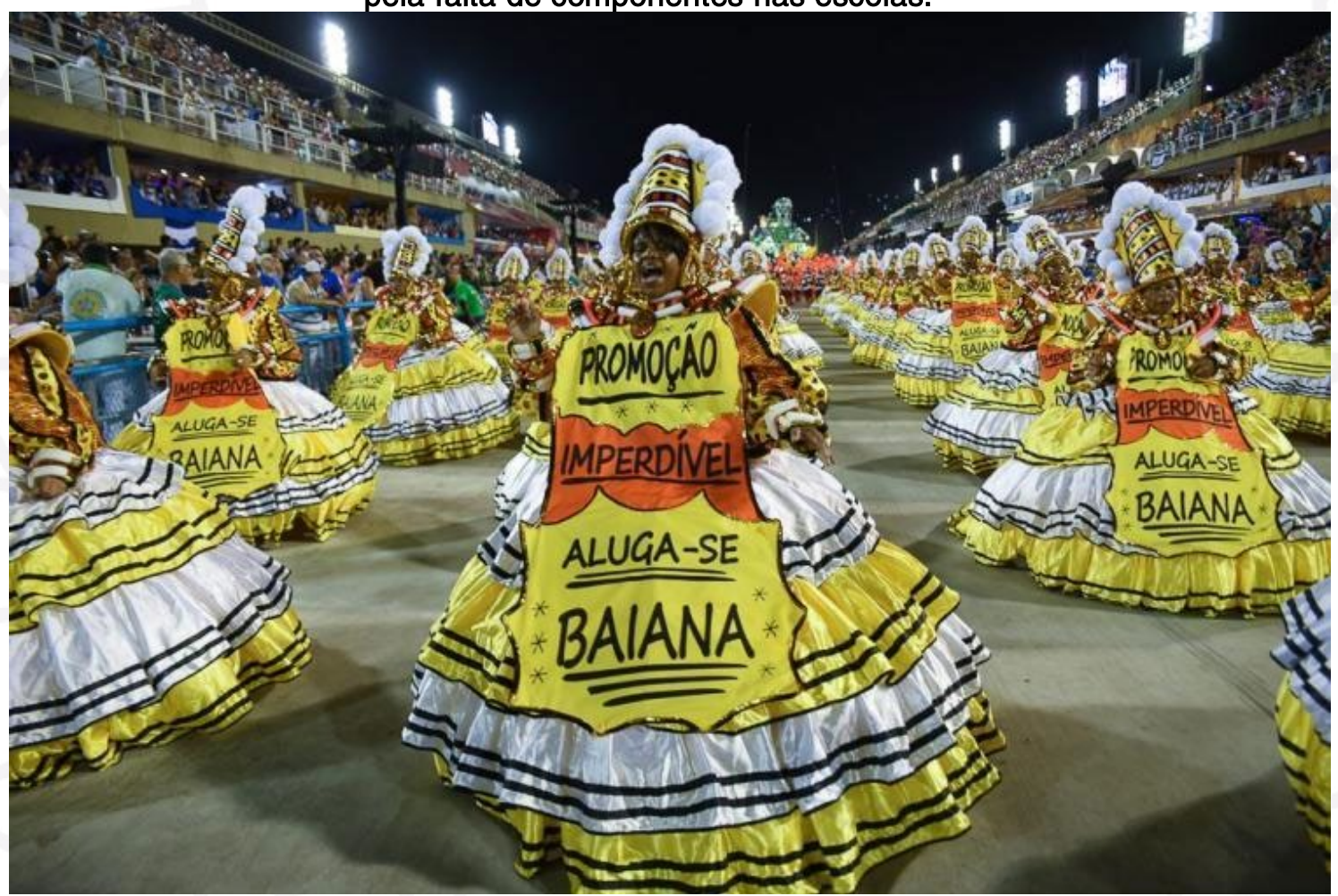

Foto: Site SRZD (Disponível em: https://www.srzd.com/carnaval/rio-de-janeiro/desfile-saoclemente-2019/. Acesso em 28 mar.2021).

Por mais que as inovações sejam sempre bem-vindas em relação aos trajes das baianas de Carnaval, é sempre importante pensar em sua forma, volume e peso, para que não sejam perdidas ainda mais componentes. Para tal, há uma necessidade urgente de se repensar estratégias, como sugere o pesquisador Felipe Ferreira:

Outras soluções precisam ser descobertas pela criatividade e engenhosidade de nossos carnavalescos. Novas regulamentações talvez possam ser pensadas no sentido de limitar tamanho e peso das fantasias. Soluções inesperadas podem sair do diálogo entre a inovação dos criadores e a sabedoria das próprias baianas. As possibilidades são muitas. O importante é perceber a tempo que um caminho diferente precisa ser descoberto com urgência. Com isso, podemos ter a certeza de que, ao contrário do que poderíamos temer, estaremos presenciando o renascimento da ala que reúne e representa tudo que mais amamos no carnaval das escolas de samba: nossas "mães" baianas (FERREIRA, 2010, p. 39).

A manutenção e conservação da tradição das matriarcas do samba depende diretamente das componentes. Preservar sua saúde e integridade física é primordial, uma vez que a cada ano elas terão que expressar sua 
dança, quando o samba tocar seu coração. A escola sugere - e algumas vezes obriga - que elas façam seu bailado coreografado durante a passagem da escola pela avenida, o que exige preparo e disposição.

\section{Referências}

ALMEIDA, Thiago Acácio de e ROCHA, Natália de Andrade. As baianas no carnaval carioca: o corpo como construção e como resistência. In: Revista Dissertar, Volume 1, Número 34, 2021, p. 67-79. Disponível em http://revistadissertar.adesa.com.br/index.php/revistadissertar/article/view/296. Acesso em 22 mar. 2021.

CABRAL, Sergio. As escolas de samba do Rio de Janeiro. Rio de Janeiro: Lazuli Editora: Companhia Editora Nacional, 2011.

CAVALCANTI, Maria Laura Viveiros de Castro. Baianas e Velha Guarda. Corpo e envelhecimento no carnaval carioca In: Corpo, envelhecimento e felicidade. Rio de Janeiro: Ed. Civilização Brasileira, 2011. p. 245-273.

FERREIRA, Felipe. O marquês e o jegue: estudo da fantasia para escolas de samba. Rio de Janeiro: Altos da Glória, 1999.

FERREIRA, Felipe. Será o fim da ala das baianas? In: Revista Beija-Flor de Nilópolis, fevereiro 2010, pp. 38-39. Disponível em:

https://issuu.com/l.I.b.lemos/docs/2010 web. Acesso em: 10 mar. 2021.

IPHAN. Dossiê Matrizes do Samba no Rio de Janeiro: partido-alto, samba de terreiro, samba-enredo. Brasília: Iphan, 2014. Disponível em:

http://portal.iphan.gov.br/uploads/publicacao/DossieSambaWeb.pdf. Acesso em 20 mar. 2021.

LIESA. Regulamento oficial dos desfiles das escolas de samba do grupo especial 2020. Disponível em: http://liesa.globo.com/downloads/memoria/outroscarnavais/2020/regulamento-2020.pdf. Acesso em: 22 mar. 2021.

LIGASP. Regulamento oficial Grupo Especial e Acesso I 2020. Disponível em: https://drive.google.com/file/d/1pePIKtaBl6csk276vogIVCaXspNU4stu/view. Acesso em: 22 mar. 2021.

MEMÓRIA em verde e rosa. Direção: Pedro Von Krüger. Brasil: Com Domínio Filmes e Formiga Produções Culturais, 2017. Amazon Prime Video (80 min). 
Da artesania à apoteose: o traje e a movimentação das componentes da ala das baianas de Carnaval

SALGUEIRO. Salgueiro 1960 - Quilombo Dos Palmares. Disponível em: https://sal60.com.br/sal60/2020/11/17/salgueiro-1960-quilombo-dos-palmares/.

Acesso em: 28 mar.2021.

URBANO, Maria Apparecida. Mães do Samba: tias baianas ou tias quituteiras.

São Paulo: Clube do Bem-Estar, 2012.

VON SIMSON, Olga Rodrigues de Moraes. Carnaval em Branco \& Negro:

Carnaval paulistano (1914-1988). Campinas: Editora Unicamp, 2007. 